\title{
An overview of survival studies in patients with heart failure
}

\author{
Paul J. Oldershaw
}

Royal Brompton National Heart and Lung Hospital, Sydney Street, London SW3 6NP, UK

\begin{abstract}
Summary: Heart failure is associated with poor prognosis, but recent large-scale investigations have generated valuable and practical information to help improve clinical management and patient survival. This review presents an overview of the findings of recent heart failure survival studies and how these may affect therapeutic strategy for patients with this condition.
\end{abstract}

\section{Introduction}

Heart failure is a highly prevalent condition associated with a poor prognosis. ${ }^{1}$ It has been estimated that 2.3 million patients in the USA and about 2 million in Germany, France and the United Kingdom are affected at any one time, giving a prevalence in society of approximately $1 \%{ }^{2,3}$ Life expectancy is dramatically shortened in patients with heart failure, and only $50 \%$ survive for 5 years after diagnosis. ${ }^{4}$ In addition, more than one-third of patients with heart failure require treatment in a hospital each year. ${ }^{5}$

Recently completed clinical investigations (SOLVD and V-HeFT-II trial) ${ }^{6,7}$ have yielded encouraging evidence that treatment with the longacting angiotensin converting enzyme (ACE) inhibitor enalapril can reduce mortality and morbidity (hospitalizations) in patients with mild to moderate grades of heart failure. These findings from the SOLVD ${ }^{6}$ and V-HeFT-II ${ }^{7}$ trials extend those of the CONSENSUS study (the Cooperative North Scandinavian Enalapril Survival Study), reported in 1987, which showed clear mortality reductions in enalapril-treated patients compared with placebo therapy in patients with severe heart failure. ${ }^{8}$ This article presents an overview of the findings of the large heart failure survival studies, and how these may affect present and future tretment of heart failure. It also explores reports of differences in the mortality reduction of patients treated with enalapril and captopril, which suggest that the effects of enalapril demonstrated in the SOLVD, V-HeFT-II and CONSENSUS studies are related to some characteristic activity of this agent rather than a class effect of all ACE inhibitors. ${ }^{9,10}$

Correspondence: P.J. Oldershaw, M.D., F.R.C.P. Accepted: 16 January 1992

\section{Review of recent studies}

\section{CONSENSUS}

ACE inhibitors had been available for several years before the results of CONSENSUS were reported and had been shown to improve symptoms and exercise capacity in patients with severe hearto failure but not necessarily prognosis. ${ }^{8,11}$ Retrospec tive analyses of placebo-controlled trials suggested, however, that ACE inhibitors might provide beneficial effects on mortality. ${ }^{12}$ To examine this possibility, the CONSENSUS trial was designed to study the effect of enalapril compared to placebo on mortality in patients with severe heart failure.

The study randomized 253 patients with severe heart failure to receive either enalapril $(n=127)$ or placebo $(n=126)$ in addition to conventional therapy. Patients recruited were classified as New York Heart Association (NYHA) class IV (symptomatic at rest) despite optimal therapy with diuretics and digoxin. Treatment with non-ACEinhibiting vasodilators was also permitted. Enalapril-treated patients experienced a $40 \%$ reduction in mortality after 6 months and a $27 \%$ reduction at the end of the study (Table I). The greatest mortality reduction (a $50 \%$ reduction in patients randomized to active treatment) was in deaths caused by progression of heart failure. At the end of the study, NYHA classification had improved in $42 \%$ of patients receiving enalapril but in only $22 \%$ of those given placebo, a statistically significant difference $(P<0.001)$. The benefits of enalapril treatment in the study were so clear-cut that the Ethical Committee recommended that enrolment and follow-up be discontinued earlier than planned. 
Table I Mortality results from CONSENSUS.* (Reproduced with permission from The CONSENSUS Trial Study Group, $N$ Engl J Med 1987, 316: 1429-1435)

\begin{tabular}{lcccccc}
\hline & \multicolumn{3}{c}{ Treatment group } \\
& $\begin{array}{c}\text { Placebo } \\
(\mathrm{n}=126)\end{array}$ & $\begin{array}{c}\text { Enalapril } \\
\text { No. }\end{array}$ & $\%$ & $\begin{array}{l}\mathrm{n}=127) \\
\text { No. }\end{array}$ & $\begin{array}{c}\text { Reductions in } \\
\text { relative risk } \\
\%\end{array}$ & $\begin{array}{c}\text { P value } \\
\text { (life-table) } \\
\text { analysis }\end{array}$ \\
\hline $\begin{array}{l}\text { Mortality at 6 months } \\
\text { (180 days) }\end{array}$ & 55 & 44 & 33 & 26 & 40 & 0.002 \\
$\begin{array}{c}\text { Mortality at 1 year } \\
\text { (360 days) }\end{array}$ & 66 & 52 & 46 & 36 & 31 & 0.001 \\
Total mortality & 68 & 54 & 50 & 39 & 27 & 0.003 \\
\hline
\end{tabular}

*In the placebo group, the mean follow-up was 237 days among the 58 survivors and 93 days among the 68 patients who died, for an overall mean of 160 days. In the enalapril group, the mean follow-up was 260 days among the 77 survivors and 147 days among the 50 patients who died, for an overall mean of 215 days.

\section{SOLVD}

Although the results of CONSENSUS were dramatic, the study was limited to patients with severe heart failure, and treatment lasted only a few months. The subsequent reports from SOLVD and V-HeFT-II have now furnished information on the use of enalapril over a longer period and in a broader range of patients, including those with mild to moderate heart failure (NYHA class II or III) ${ }^{6,7}$ The treatment arm of SOLVD examined more than 2,500 patients of whom approximately $90 \%$ were classified as NYHA class II or III. Because the study was designed as a long-term examination of the effects of treatment on mortality and disease progression, the investigators recruited patients who were in a stable clinical condition and able to tolerate long-term treatment. Before randomization, all patients were initially given $2.5 \mathrm{mg}$ of enalapril twice daily for 2-7 days to identify those unable to comply with the regimen or to tolerate active drug. ${ }^{6}$ After this initial phase, patients were given matching placebo for 14-17 days to allow identification and exclusion of those whose clinical condition worsened on withdrawal of the drug. Following randomization, patients received double-blind treatment with either placebo $(n=1284)$ or enalapril $(n=1285)$. Double-blind treatment was given in addition to conventional therapy for heart failure, which generally consisted of diuretics, digoxin and vasodilators (but not other ACE inhibitors).

Enalapril treatment was initiated at a dosage of $2.5 \mathrm{mg}$ or $5.0 \mathrm{mg}$ twice daily based on the investigators' assessment of the patients' clinical condition. The dosage was titrated to $10 \mathrm{mg}$ twice daily in patients with stable renal function who did not develop symptomatic hypotension. If symptoms of heart failure did not resolve with this regimen, increased doses of diuretics or digoxin were recommended as the first step. If maximal therapy with these agents was considered ineffective, open-label treatment with an ACE inhibitor was allowed and double-blind therapy was discontinued. The primary aim of the trial was to assess the effect of study treatment on mortality, although an important additional endpoint was hospitalization for heart failure.

Following completion of the study, the average follow-up period was 41.4 months (range 22-55 months). A reduction in mortality and hospitalization due to heart failure was evident in the enalapril group after 3 months of randomization (Table II) and continued throughout treatment. The difference in mortality appeared to be most marked in the first 24 months after randomization.

At the end of the scheduled follow-up, 452 patients in the active-treatment group and 510 patients in the placebo group had died. This outcome represents a risk reduction of $16 \%$ $(P<0.0036)$. The largest mortality reduction was for deaths attributed to progression of heart failure (risk reduction $22 \%, P<0.0045$ ), although death due to other causes also declined (Table III).

A significant reduction in the combined endpoint of death or hospitalization for congestive heart failure was also observed in enalapril-treated patients (Table II). The overall risk reduction was $26 \%(P<0.0001)$. Overall, 971 hospitalizations were required in the placebo group, compared to 683 in the enalapril-treatment group. The total number of patients requiring hospitalization was 470 in the placebo group and 332 in the activetreatment group. Interestingly, the difference in mortality was observed only among patients hospitalized at least once during the trial. Based on 
Table II Effect of treatment on mortality and hospitalization for heart failure in the SOLVD treatment arm. (Adapted with permission from The SOLVD Investigators, $N$ Engl J Med 1991, 325: 293-302)

\begin{tabular}{|c|c|c|c|c|c|c|}
\hline \multirow[b]{2}{*}{$\begin{array}{l}\text { Months of } \\
\text { follow-up }\end{array}$} & \multicolumn{3}{|c|}{ Mortality } & \multicolumn{3}{|c|}{$\begin{array}{c}\text { Death or hospitalization for } \\
\text { heart failure }\end{array}$} \\
\hline & $\begin{array}{r}\text { Placebo } \\
\text { Nur }\end{array}$ & $\begin{array}{l}\text { Enalapril } \\
\text { nber }\end{array}$ & $\begin{array}{c}\text { Risk } \\
\text { reduction } \\
\%\end{array}$ & $\begin{array}{r}\text { Placebo } \\
\mathrm{Nu}\end{array}$ & $\begin{array}{l}\text { Enalapril } \\
\text { nber }\end{array}$ & $\begin{array}{c}\text { Risk } \\
\text { reduction } \\
\%\end{array}$ \\
\hline 3 & 69 & 47 & 33 & 164 & 92 & 46 \\
\hline 6 & 126 & 91 & 29 & 259 & 150 & 45 \\
\hline 12 & 201 & 159 & 23 & 401 & 262 & 40 \\
\hline 24 & 344 & 277 & 23 & 559 & 434 & 30 \\
\hline 36 & 450 & 396 & 16 & 680 & 555 & 28 \\
\hline 48 & 504 & 443 & 17 & 731 & 607 & 27 \\
\hline Overall & 510 & $\begin{array}{c}452 \\
P=0.00\end{array}$ & $36^{16}$ & 736 & $\begin{array}{c}613 \\
P<0.00\end{array}$ & 26 \\
\hline
\end{tabular}

Table III Number of deaths, causes of death, and number of patients who died or were hospitalized for congestive heart failure (CHF), according to treatment in SOLVD. (Adapted with permission from The SOLVD Investigators, $N$ Engl J Med 1991, 325: 293-302)

\begin{tabular}{lrrrrrr}
\hline & \multicolumn{7}{c}{ Placebo } \\
Variable & \multicolumn{7}{c}{$\begin{array}{c}\text { Enalapril } \\
\text { No. }\end{array}$ (\%) } & $\begin{array}{c}\text { Risk } \\
\text { reduction } \\
(\%)\end{array}$ & P value \\
\hline Randomized patients & 1284 & $(100.0)$ & 1285 & $(100.0)$ & - & - \\
Deaths & 510 & $(39.7)$ & 452 & $(35.2)$ & 16 & $<0.0036$ \\
Deaths or hospitalizations for CHF & 736 & $(57.3)$ & 613 & $(47.7)$ & 26 & $<0.0001$ \\
Cardiovascular deaths & 461 & $(35.9)$ & 399 & $(31.1)$ & 18 & $<0.002$ \\
Cardiac & 441 & $(34.3)$ & 376 & $(29.3)$ & 19 & $<0.0015$ \\
$\quad$ Arrhythmia without worsening CHF & 113 & $(8.8)$ & 105 & $(8.2)$ & 10 & - \\
$\quad$ Heart failure or arrhythmia with CHF & 251 & $(19.5)$ & 209 & $(16.3)$ & 22 & $<0.0045$ \\
$\quad$ Myocardial infarction & 53 & $(4.1)$ & 40 & $(3.1)$ & 28 & $<0.07$ \\
$\quad$ Other & 24 & $(1.9)$ & 22 & $(1.7)$ & - & - \\
Stroke & 11 & $(0.9)$ & 10 & $(0.8)$ & - & - \\
Other vascular or unknown & 9 & $(0.7)$ & 13 & $(1.0)$ & - & - \\
Noncardiovascular deaths & 49 & $(3.8)$ & 53 & $(4.1)$ & - & - \\
\hline
\end{tabular}

these observations, the investigators hypothesized that prevention of hospitalization for heart failure could be an effect of enalapril that is linked to the ability to reduce mortality.

More patients taking placebo than taking enalapril received other vasodilators during the trial to treat worsening heart failure. Therefore, the investigators reported that the risk reductions of $16 \%$ for mortality and $26 \%$ for the combined outcome of mortality or hospitalization for heart failure determined by intention-to-treat analysis over the course of the trial probably underestimate the actual benefits of the drug.

The effects of active treatment were consistent among most of the subgroups in the study, based on serum sodium concentration, cause of heart failure, or severity of heart failure. In subgroups based on ejection fraction at baseline, the effects of enalapril on mortality and hospitalizations appeared to be greatest in patients in the two tertiles with lowest ejection fraction. In the tertile with least depressed ejection fraction, a trend toward fewer hospitalizations was observed in patients alive at the end of the study, and the $95 \%$ confidence intervals included the possibility of a $20 \%$ risk reduction for mortality or hospitalization as a result of worsening heart failure.

\section{V-HeFT-II}

V-HeFT-II compared the effects on mortality of enalapril with those of the vasodilator combination 
of hydralazine and isosorbide dinitrate. ${ }^{7}$ The majority of patients in this study had heart failure classified as NYHA class II or III. Following randomization, 403 patients received double-blind treatment with enalapril, and 401 received the vasodilator combination. Because this trial compared enalapril treatment with a treatment regimen already proven to reduce mortality, ${ }^{13} \mathrm{~V}$-HeFT-II also included comparisons of the effects of treatment on physiological endpoints (peak oxygen consumption during excerise and left ventricular ejection fraction) in addition to mortality.

The mortality curves of the two treatment arms separated early after randomization, and the relative reduction in mortality for patients treated with enalapril continued for up to 4 years of the study. Mortality after 2 years (a major predetermined endpoint of the study) was significantly lower in the enalapril group $(18 \%)$ than in the hydralazine/isosorbide dinitrate treated group $(25 \%)$, a risk reduction of $28 \%(P=0.016)$.

Because V-HeFT-II was a comparison of two active treatments added to conventional therapy, the authors drew particular attention to the magnitude of the mortality-reducing effect by comparing the results with those of V-HeFT-I, a placebocontrolled study. Because the patient populations in both trials were homogenous and the mortality curves for patients randomized to receive hydralazine/isosorbide dinitrate were reproducible in both trials (Table IV), the authors compared mortality results of the two studies and found that adding enalapril to conventional treatment reduced mortality after 1 year to $9 \%$ from a historic value of $20 \%$ with placebo in V-HeFT-I.

In V-HeFT-II, the nonspecific vasodilator combination produced significantly more improvement in exercise performance and left ventricular ejection fraction, indicating more effective vasodilatation than with enalapril, despite the clearly greater reduction in mortality in patients receiving enalapril. The authors suggest that this observation may mean that not all therapeutic endpoints assessed in trials of heart failure treatment are affected in the same way and that the beneficial effect of enalapril on mortality may be a result of a specific nonvasodilator mechanism.

\section{Other studies}

There is further interesting evidence to suggest that the degree of ACE inhibition produced by enalapril may be linked to the mortality-reducing effect. ${ }^{9,10,14}$ One report, from a retrospective analysis of baseline therapy in the Xamoterol in Severe Heart Failure Study, reported a greater probability of survival for patients taking enalapril than for those taking captopril. ${ }^{9}$ The excess mortality in captopril-treated patients could not be related to factors considered indices of heart failure severity. After examining the dosage schedules for the two ACE inhibitors, the authors proposed that, in general, patients on captopril may have been taking an insufficient dose or receiving an insufficient number of daily doses. Because enalapril has greater potency and longer duration of action as an inhibitor of ACE, differences in mortality may be attributable to differences in the blockade of the renin - angiotensin system.

Differences in mortality have also been reported when low and high doses of enalapril have been compared in patients with severe heart failure. ${ }^{14}$ Fewer patients died or required hospital treatment for heart failure while taking higher doses that? would be expected to inhibit ACE to a greater extent. Moreover, ACE inhibitors have characteristic profiles of activity with respect to inhibition of tissue and circulatory renin-angiotensin systems. ${ }^{15}$ Because the mortality reductions seen with enalapril may be related to the extent of inhibition of ACE, these properties should not be considered a class effect common to all ACE inhibitors unless clinical evidence becomes available to support this view. ${ }^{10}$

Table IV Cumulative mortality for V-HeFT-I and V-HeFT-II. (Reproduced with permission from Cohn et al., $N$ Engl J Med 1991, 325: 303-310)

\begin{tabular}{|c|c|c|c|c|c|}
\hline \multirow[b]{2}{*}{ Study group } & \multirow[b]{2}{*}{$\begin{array}{c}\text { No. of } \\
\text { patients }\end{array}$} & \multicolumn{4}{|c|}{ Cumulative mortality } \\
\hline & & 1 year & 2 yea & 3 years & 4 years \\
\hline \multicolumn{6}{|l|}{ V-HeFT-I } \\
\hline Placebo & 273 & 20 & 34 & 47 & 54 \\
\hline Hydralazine isosorbide dinitrate & 186 & 12 & 26 & 36 & 50 \\
\hline \multicolumn{6}{|l|}{ V-HeFT-II } \\
\hline Hydralazine isosorbide dinitrate & 401 & 13 & 25 & 36 & 47 \\
\hline Enalapril & 403 & 9 & 18 & 31 & 42 \\
\hline
\end{tabular}




\section{Conclusion}

The consistency of the effect seen with enalapril in these independent, well-conducted survival studies provides good evidence that this agent should be regarded as a new cornerstone in the treatment of heart failure. Addition of enalapril to conventional therapy with diuretics and digoxin has been clearly shown to improve the prognosis of patients with heart failure of all grades. Medical practitioners now have firm clinical evidence on which to base choices of treatment for heart failure. The results of the SOLVD trial suggest that 3 years of enalapril treatment in 1,000 heart failure patients similar to those enrolled in SOLVD might prevent about 50 premature deaths and an additional 350 hospitalizations. $^{6}$

\section{References}

1. Kannel, W.B. \& Belanger, A.J. Epidemiology of heart failure. Am Heart $J$ 1991, 12: 951 -957.

2. Dinkel, R., Buchner, K. \& Holtz, J. Chronic heart failure socioeconomic relevance in the Federal Republic of Germany. Munch Med Wochenschr 1989, 131: 686-689.

3. Rowlands, D.J. Cardiac failure. Curr Opin Cardiol 1986, 1: 331-333.

4. McFate-Smith, W. Epidemiology of congestive heart failure. Am J Cardiol 1985, 55: 3A-8A

5. Ghati, J.K., Cooper, R. \& Ford, E. Trends in hospitalization rates for heart failure in the United States 1973-1986. Evidence for increasing population prevalance. Arch Intern Med 1990, 150: 769-773.

6. The SOLVD Investigators. Effect of enalapril on survival in patients with reduced left ventricular ejection fractions and congestive heart failure. $N$ Engl J Med 1991, 325: 293-302.

7. Cohn, J.N., Johnson, G., Ziesche, S. et al. A comparison of enalapril with isosorbide-dinitrate in the treatment of chronic congestive heart failure. $N$ Engl J Med 1991, 325: 303-310.

8. The CONSENSUS Trial Study Group. Effects of enalapril on mortality in severe heart failure: Results of the Cooperative North Scandinavian Enalapril Survival Study (CONSENSUS). $N$ Engl $J$ Med 1987, 316: 1429-1435.

9. Pouleur, H., Rousseau, M.F., Oakley, C. \& Ryden, L. for the Xamoterol in Severe Heart Failure Study Group. Differences in mortality between patients treated with captopril or enalapril in the Xamoterol in Severe Heart Failure Study. Am J Cardiol 1991, 68: 71-74.

10. Pitt, B. Angiotensin-converting inhibitors in patients with congestive heart failure. A class effect. Am J Cardiol 1991, 68: 106-108.

11. Captopril Multicentre Research Group. A placebo-controlled trial of captopril in refractory chronic congestive heart failure. J Am Coll Cardiol 1983, 2: 755-763.

12. Furberg, C.D. \& Yusuf, S. Effect of vasodilators on survival in chronic congestive heart failure. Am $J$ Cardiol 1875, 55: 1110-1113.

13. Cohn, J.N., Archibald, D.G., Ziesche, S. et al. Effect of vasodilator therapy on mortality in chronic congestive heart failure: Results of a Veterans Administration Cooperative Study. $N$ Engl J Med 1986, 314: 1547-1552.

14. Vagelos, R., Nejedly, M., Wilson, K., Yee, Y.G. \& Fowler, M. Comparison of low vs high dose enalapril therapy for patients with severe congestive heart failure (CHF). J Am Coll Cardiol 1991, 2: 275A.

15. Cushman, D.W., Wang, F.L., Funk, W.K., Harvey, C.M. \& De Forrest, J.M. Differentiation of angiotensin-converting enzyme (ACE) inhibitors by their selective inhibition of ACE in physiological important target organs. Am $J$ Hypertens 1989, 2: P294-306. 